\title{
Comparison between Use of PSA Kinetics and Bone Marrow Micrometastasis to Define Local or Systemic Relapse in Men with Biochemical Failure after Radical Prostatectomy for Prostate Cancer
}

\author{
Nigel P Murray ${ }^{1 *}$, Eduardo Reyes ${ }^{2}$, Cynthia Fuentealba ${ }^{3}$, Nelson Orellana ${ }^{4}$, \\ Omar Jacob ${ }^{3}$
}

\begin{abstract}
Background: Treatment of biochemical failure after radical prostatectomy for prostate cancer is largely empirically based. The use of PSA kinetics has been used as a guide to determine local or systemic treatment of biochemical failure. We here compared PSA kinetics with detection of bone marrow micrometastasis as methods to determine local or systemic relapse. Materials and Methods: A transversal study was conducted of men with biochemical failure, defined as a serum PSA $>0.2 \mathrm{ng} / \mathrm{ml}$ after radical prostatectomy. Consecutive patients having undergone radical prostatectomy and with biochemical failure were enrolled and clinical and pathological details were recorded. Bone marrow biopsies were obtained from the iliac crest and touch prints made, micrometastasis $(\mathrm{mM})$ being detected using anti-PSA. The clinical parameters of total serum PSA, PSA velocity, PSA doubling time and time to biochemical failure, age, Gleason score and pathological stage were registered. Results: A total of 147 men, mean age 71.6 \pm 8.2 years, with a median time to biochemical failure of 5.5 years (IQR 1.0-6.3 years) participated in the study. Bone marrow samples were positive for micrometastasis in 98/147 (67\%) of patients at the time of biochemical failure. The results of bone marrow micrometastasis detected by immunocytochemistry were not concordant with local relapse as defined by PSA velocity, time to biochemical failure or Gleason score. In men with a PSA doubling time of $<$ six months or a total serum PSA of $>2,5 \mathrm{ng} / \mathrm{ml}$ at the time of biochemical failure the detection of bone marrow micrometastasis was significantly higher. Conclusions: The detection of bone marrow micrometastasis could be useful in defining systemic relapse, this minimally invasive procedure warranting further studies with a larger group of patients.
\end{abstract}

Keywords: Prostate cancer - biochemical failure - bone marrow micrometastasis - systemic or local relapse

Asian Pac J Cancer Prev, 16 (18), 8387-8390

\section{Introduction}

Biochemical failure (BF) after radical prostatectomy for prostate cancer, occurs in approximately $30 \%$ of patients. Although there have been cases described of BF of up to 10-15 years after surgery, it usually occurs within 12 months post surgery, with $95 \%$ occurring within the first five years (Pound et al., 1997; Han et al., 2003). Although different guidelines have defined biochemical failure with differing levels of serum PSA, the NCCN guidelines (2014) use a level of $0.2 \mathrm{ng} / \mathrm{ml}$ while the UK NICE guidelines recomended a cutoff point of $0.4 \mathrm{ng} / \mathrm{ml}$ as did Amling et al (2001), who reported that only $49 \%$ of men with a PSA of $0.2 \mathrm{ng} / \mathrm{ml}$ progressed within a three year period. Freedland et al (2003) showed that a PSA of $>0.2 \mathrm{ng} / \mathrm{ml}$ is appropriate to define PSA recurrence, reporting that $100 \%$ of such patients had a risk of PSA progession within 3 years. Once biochemcial failure has occurred determining local versus systemic failure is critical for defining optimal treatment and subsequent management strategy.

Recomendations for the detection of systemic spread differ; the NCCN suggests bone scan CT/MRI scans, ProstaScint ${ }^{\circledR}$ scan, prostate bed biopsy and PSA doubling time as posible methods to differentiate between local and systemic relapse. However, UK NICE 2015 guidelines do not recommend prostate bed biopsy after radical prostatectomy, as only $41-55 \%$ of cases will have a positive biopsy (Scattoni et al., 2004). MRI scanning may be useful in defining local recurrence but not routinely recommended and a bone scan is only positive in 1-3\% of men with a PSA $<10 \mathrm{ng} / \mathrm{ml}$ at the time of detected failure (Okotie et al., 2004; Dotan et al., 2005).

Analysis of PSA kinetics has been suggested to be the best method for determing the pattern of relapse, classifying it as local or systemic recurrence. Time to 
PSA failure (Aus et al., 2006); PSA velocity (Partin et al., 1994); PSA doubling time (Freedland et al., 2007) have all been suggested as PSA based parameters to define local or systemic relapse.

The use of bone marrow micrometastasis detected in bone marrow biopsy "touch preps" may be a better guide in defining local or systemic failure. We present a study of men with biochemical failure after radical prostatectomy, the results of PSA kinetics and the comparison with the detection of micrometastasis in bone marrow samples.

\section{Materials and Methods}

All men with biochemical failure after radical prostatectomy and referred to the Instituto de BioOncology, Santiago between January 2008 and July 2012, with histologically proven prostate cancer were asked to participate. Inclusion criteria were as follows: biopsy proven prostate cancer treated by radical prostatectomy, without androgen blockade or DES, at least six months post-surgery, bone scan negative for metastasis, biochemical failure was defined as a total serum PSA $>0.2 \mathrm{ng} / \mathrm{ml}$ on at least two occasions separated by one month, written informed consent.

1. PSA kinetics to define local or systemic relapse: the following criteria were used to define a local relapse; the time to biochemical failure more than six months or more than two years, a PSA velocity of less than $0.75 \mathrm{ng} / \mathrm{ml} / \mathrm{year}$ and a total serum PSA of less than $2.5 \mathrm{ng} / \mathrm{ml}$. PSA doubling times were calculated in patients were the data were available, a local relapse being defined as a doubling time of more than 6 months. Systemic relapse was therefore defined as; biochemical failure occurring less than 6 months or less than two years after radical prostatectomy, a PSA velocity $>0.75 \mathrm{ng} / \mathrm{ml} /$ year, a total PSA $>2.5 \mathrm{ng} / \mathrm{ml}$ or a PSA doubling time of less than 6 months.

2. i) bone marrow biopsy: bone marrow biopsy samples were obtained from the posterior superior iliac crest and used to make three "touch preps". The sialinized slides (DAKO, USA), were dried in air for 24 hours and fixed in a solution of $70 \%$ ethanol, $5 \%$ formaldehyde, and $25 \%$ phosphate buffered saline (PBS) $\mathrm{pH} 7.4$ for five mintues and finally washed three times in PBS pH 7.4. ii) Immunocytochemistry: micrometastasis were detected using a monoclonal antibody directed against PSA, clone 28A4 (Novocastro Laboratory, UK), and identified using an alkaline phosphatase-anti alkaline phosphatase based system (LSAB2, DAKO, USA), with new fuchsin as the chromogen. Positive samples underwent a second process with anti-CD45 clone $2 \mathrm{~B} 11+\mathrm{PD} 7 / 26$ (DAKO, USA) and were identified with a peroxidase based system(LSAB2,DAKO, USA) with DAB (3,3 diaminobenzidine tetrahydrochloride) as the chromogen. A micrometastasis was defined according to the criteria of ISHAGE (International Society of Hemotherapy and Genetic Engineering) (Borgen et al., 1999), and were positive for PSA and negative for CD45.

Slides were analyzed manually, stained cells were photographed using a digital camera and from the digital images determined if micrometastasis were present or absent by one trained observer (Figure 1,2)
Statistical analysis: Descriptive statistics were used to analyze the demographic variables, Student T-Test for the differences between groups and Chi squared for differences in frequency, all tests were two tailed and $\mathrm{p}<0.05$ was considered to be statistically significant and was performed using the online programe Vassarcalc.

Ethical Considerations: The study was approved by the local ethics committee and in complete agreement with the Declaration of Helsinki. All patients provided written informed consent.

\section{Results}

147 men participated with a mean age of $71.6 \pm$ 8.2 years, a median serum PSA detected at the time of biochemical failure of $0.92 \mathrm{ng} / \mathrm{ml}$ (IQR $0.2-2.11 \mathrm{ng}$ / $\mathrm{ml}$ ), and a median time to biochemical failure of 5.5 years (IQR 1.0-6.3 years). Bone marrow samples were positive for micrometastasis in 69/111 (62\%) of men with Gleason score $\leq 6$ prostate cancer, 18/23 $(78 \%)$ with a Gleason score 7 prostate cancer and 11/13 (85\%) of men with a Gleason score $\geq 8$ prostate cancer $(\mathrm{p}=0.12$, Chi squared for trends). a) time to biochemical failure (Table 1): Using a cutoff value of six months and two years there was no significant difference in the frequency of micrometastasis detected between groups. b) PSA velocity: Using a cutoff value of $0.75 \mathrm{ng} / \mathrm{ml} /$ year there was no difference in the frequency of micrometastasis detected (Table 2) ( $\mathrm{p}=0.20$, OR 0.61 95\% CI 0.29-1.31). c) comparison with the total serum PSA value at the time relapse was detected with the presence of bone marrow micrometastasis. Bone marrow micrometastasis were significantly more frequently detected in men with a total serum PSA $>2.5 \mathrm{ng} / \mathrm{ml}$ at the time that biochemical failure was detected (Table 3), $(\mathrm{p}=0.049$; OR $0.3995 \%$ CI 0.15-1.01). d) PSA doubling time: 70 men (47.6\%) of patients had sufficient data for a PSA doubling time to be

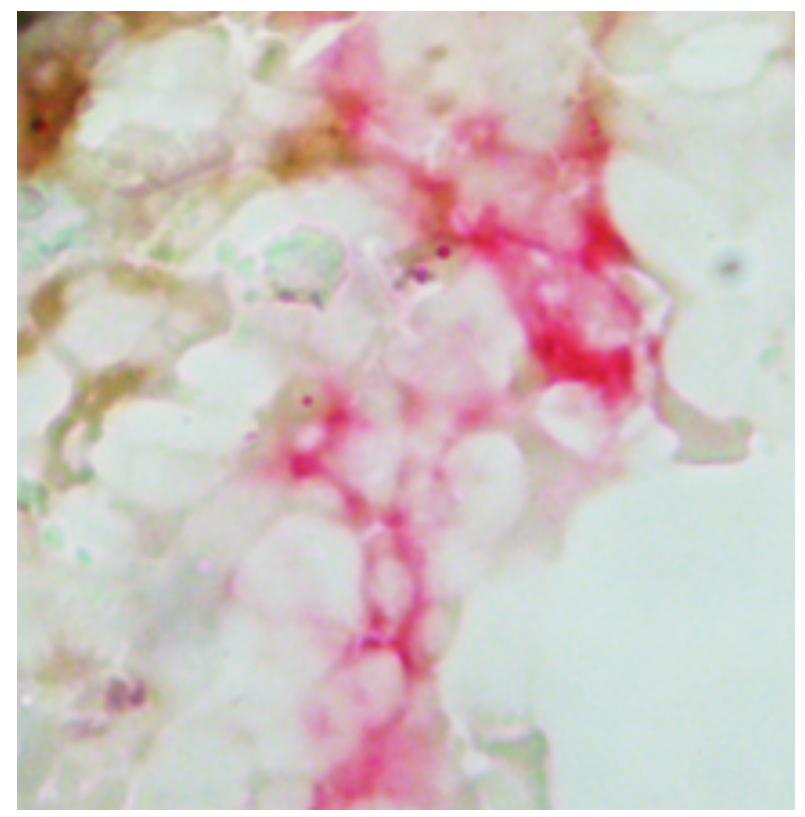

Figure 1. micrometastasis in bone marrow PSA positive (red) 
PSA Kinetics and Bone Marrow Micrometastasis to Define Relapse in Men after Radical Prostatectomy for Prostate Cancer Table 1. Comparison between the presence of bone marrow micrometastasis and time to biochemical failure

\begin{tabular}{|c|c|c|c|c|c|c|}
\hline & $\mathrm{BF}<6$ months & $\mathrm{BF}>6$ months & & $\mathrm{BF}<2$ years & $\mathrm{BF}>2$ years & \\
\hline $\mathrm{mM}(+)$ & 26 & 72 & & 51 & 47 & \\
\hline mM (-) & 13 & 36 & & 19 & 30 & \\
\hline Total & 39 & 108 & $\mathrm{p}=0.99$ & 70 & 77 & $\mathrm{p}=0.16$ \\
\hline
\end{tabular}

*mM =micrometastasis; $\mathrm{BF}=$ biochemical failure

Table 2. Comparison between PSA Velocity and the Presence of Micrometastasis in Bone Marrow

\begin{tabular}{lccc}
\hline & $\begin{array}{c}\text { PSA velocity } \\
<0.75 n g / \text { ml } / \text { year }\end{array}$ & $\begin{array}{c}\text { PSA velocity } \\
\geq 0.75 n g / m l / y e a r\end{array}$ & Total \\
\hline $\mathrm{mM}(+)$ & 61 & 37 & 98 \\
$\mathrm{mM}(-)$ & 35 & 14 & 49 \\
& 96 & 51 & 147 \\
& & & $\mathrm{p}=0.20$ \\
\hline
\end{tabular}

Table 3. Comparison between Total Serum PSA at Ime of Relapse and Presence of Micrometastasis in Bone Marrow

\begin{tabular}{lccl}
\hline & PSA $<2.5 \mathrm{ng} / \mathrm{ml}$ & $\mathrm{PSA} \geq 2.5 \mathrm{ng} / \mathrm{ml}$ & Total \\
\hline $\mathrm{mM}(+)$ & 72 & 26 & 98 \\
$\mathrm{mM}(-)$ & 43 & 6 & 49 \\
Total & 115 & 32 & 147 \\
& & & $\mathrm{p}=0.049$ \\
\hline
\end{tabular}

*mM $=$ micrometastasis

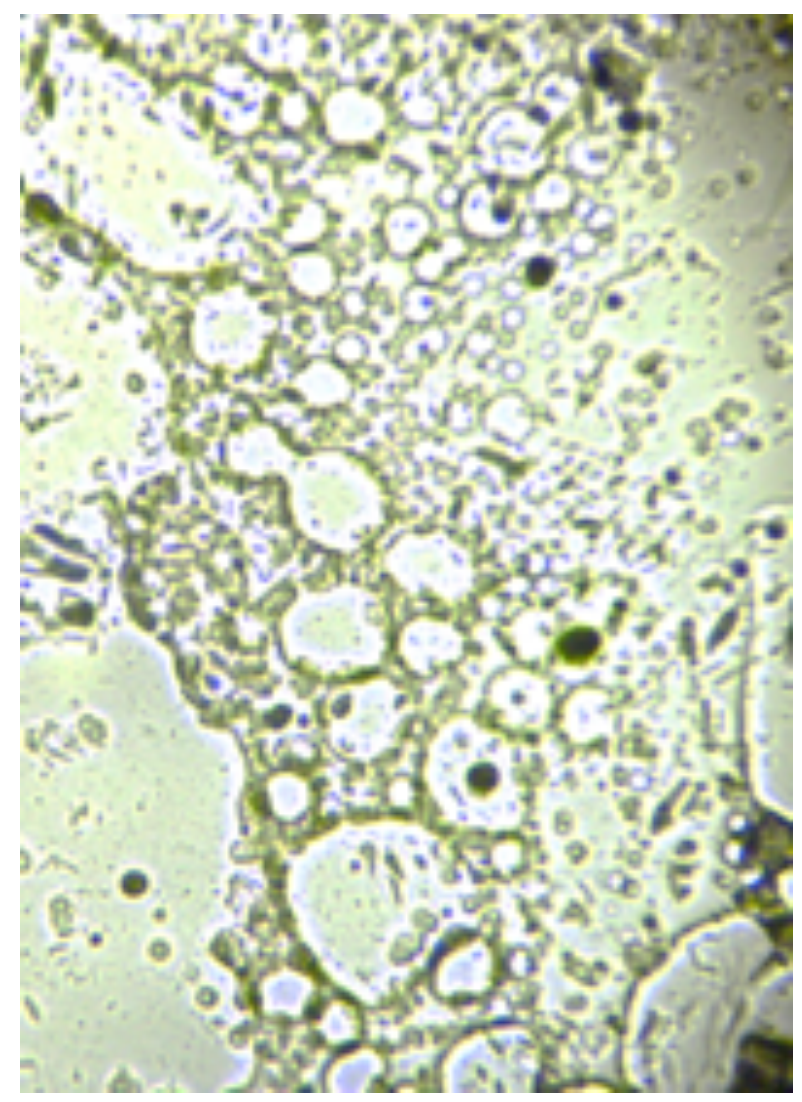

Figure 2. bone marrow negative for micrometastasis

calculated, with an average doubling time of $47.5 \pm 25.5$ months. 27/70 (38.6\%) men had a doubling time of less than 6 months and had a significantly higher frequency of bone marrow micrometastasis detected; $14 / 27$ (51.9\%) versus 3/43 (7.0\%). (p<0.001; OR 14.4 95\% CI 3.6-58.0). The remaining $43(61.4 \%)$ men had a doubling time of $>18$ months.

\section{Discussion}

At present, bone scan negative patients with biochemical failure are treated empirically, although studies using different PSA parameters have shown some utility in differentiating between local and systemic relapse. Radiological imaging with PET-CT or immunoscintigrams has not been verified in comparison with other radiological studies such as magnetic resonance.

A PSA doubling time of less than six months was associated with the presence of bone marrow micrometastasis. However the question of how to estimate PSA doubling time is variable, as to whether the values of serum PSA should be consecutive and over what time period should this PSA determination be conducted. Complicating this further is the fact that PSA values can fluctuate independent of treatment and the kinetics of PSA elevations in more than one third of patients follow higher order kinetics and are not linear (Hamilton et al., 2008).

The presence of prostate cells, as determined by immunocytochemistry, in the bone marrow is associated with an increased frequency of biochemical failure (Wood et al., 1997). The morbidity and mortality of a bone marrow biopsy is low, with a reported adverse event rate of $0.04 \%$ (Bain, 2003), the use of touch preps avoids the necessity of decalcification of the sample and thus avoids destruction of epitopes. Possibly more important is that prostate cells detected in bone marrow aspirates may not represent true micrometastasis; having the same phenotype as cells circulating in the blood but different from those found in bone marrow biopsies (Murray et al., 2012). The method is simple and can be performed in the routine immunocytochemistry laboratory of a general hospital. The method is not dependent on previous results and gives the treating urologist a yes/no answer to the question of systemic spread. All patients with bone marrow involvement do not go on to present with macrometastatic disease, the concept of dormancy whereby the normal physiological mechanisms of the host are able to control the cancer until there are changes in the tumor phenotype and/or growth, whereby the tumor escapes the host control mechanisms.

PSA kinetics were not able to discriminate between patients with or without prostate cells detected in bone marrow samples. In those patients that PSA kinetics suggested local relapse, up to a third had micrometastasis in the bone marrow detected.

The results suggest that the detection of micrometastasis 
Nigel P Murray et al

in the bone marrow may aide in the decision as to which treatment to use for biochemical failure after radical prostatectomy. Their presence would suggest systemic spread and thus local radiotherapy would not be appropriate. The results warrant larger scale studies and follow up to determine whether macrometastasis developed in men treated locally for biochemical failure.

\section{Acknowledgements}

The authors wish to thank Mrs. Ana María Palazuelos for help in the writing of this manuscript.

\section{References}

Amling CL, Bergstralh EJ, Blute ML, et al (2001). Defining PSA progression after radical prostatectomy. What is the most appropriate cutoff? J Urol, 165, 1146

Aus G, Abbou CC, Bolla M, et al (2006). Guidelines on Prostate Cancer.Ed EUA; Arnhem, EAU Guidelines Office. Chapter, $\mathbf{1}, 106$

Bain BJ (2003). Bone marrow biopsy morbidity and mortality. Br J Haematol, 121, 949-51

Borgen E, Naume B, Nesland JM, et al (1999). Standardization of the immunocytochemical detection of cancer cells in $\mathrm{BM}$ and blood. I. Establishment of objective criteria for the evaluation of immunostained cells. Cytotherapy, 1, 377-88.

Dotan ZA, Bianco FJ Jr, Rabini F, et al (2005). Pattern of PSA failure dictates the probability of a positive bone scan in patients with an increasing PSA after radical prostatectomy. J Clin Oncol, 23, 1962-8

Freedland SJ, Sutter ME, Dorey F, et al (2003). Defining the ideal cutoff point for determining PSA recurrence after radical prostatectomy. Urol, 61, 365-369

Freedland SJ, Humphries EB, Mangold LA, et al (2007). Death in patients with recurrent prostate cancer after radical prostatectomy. PSA doubling time subgroups and their associated contributions to all cause mortality. JClin Oncol, 25, 1765-71

Hamilton RJ, Aronson WJ, Terris MK, et al (2008). Limitations of PSA doubling time following biochemical recurrence after radical prostatectomy: results from the SEARCH database. J Urol, 179, 1785-9.

Han M, Partin AW,Zahurak MW, et al (2003). Biochemical (PSA) recurrence probability following radical prostatectomy for clinically localized prostate cancer. J Urol, 169, 517-23

Murray NP, Reyes E, Tapia P, et al (2012). Redefining micrometastasis in prostate cance- a comparison of circulating prostate cells, bone marrow disseminated tumor cells and micrometastasis: implications in determining local or systemic treatment for biochemcial failure after radical prostatectomy. Int J Mol Med, 30, 896-904

NCCN (2014) prostate cancer guidelines. www.nccn.org NICE UK prostate cancer guidelines 2015. www.ncen.org

Okotie OT, Aronson WJ, Wieder JA, et al (2004). Predictors of metastatic disease in men with biochemical failure following radical prostatectomy. J Urol, 171, 2260-4

Partin AW, Pearson JD, Landis PK, et al (1994). Evaluation of serum PSA velocity after radical prostatectomy to distinguish local recurrence from systemic metastasis. Urol, 43, 649-59

Pound CR, Partin AW, Epstein JI, et al (1997). PSA after anatomic radical retropubic prostatectomy. Patterns of recurrence and cancer control. Urol Clin North Amm, 24, 395-406

Scattoni V, Montorsi F, Picchio L, et al (2004). Diagnosis of locasl recurrence after radical prostatectomy. BJU Int, 93,
680-8

Wood DP, Banerjee M (1997). Presence of circulating prostate cells in the bone marrow of patients undergoing radical prostatectomy is predictive of disease free survival. J Clin Oncol, 15, 3451-7. 